\title{
Detection and verification of malting quality QTLs using wild barley introgression lines
}

\author{
Inga Schmalenbach · Klaus Pillen
}

Received: 17 September 2008/ Accepted: 9 February 2009/Published online: 3 March 2009

(C) The Author(s) 2009. This article is published with open access at Springerlink.com

\begin{abstract}
A malting quality quantitative trait locus (QTL) study was conducted using a set of 39 wild barley introgression lines (hereafter abbreviated with S42ILs). Each S42IL harbors a single marker-defined chromosomal segment from the wild barley accession 'ISR 42-8' (Hordeum vulgare ssp. spontaneum) within the genetic background of the elite spring barley cultivar 'Scarlett' (Hordeum vulgare ssp. vulgare). The aim of the study was (1) to verify genetic effects previously identified in the advanced backcross population S42, (2) to detect new QTLs, and (3) to identify S42ILs exhibiting multiple QTL effects. For this, grain samples from field tests in three different environments were subjected to micro malting. Subsequently, a line $\times$ phenotype association study was performed with the S42ILs in order to localize putative QTL effects. A QTL was accepted if the trait value of a particular S42IL was significantly $(P<0.05)$ different from the recurrent parent as a control, either across all tested environments or in a particular environment. For eight malting quality traits, altogether 40 QTLs were localized, among which 35 QTLs $(87.5 \%)$ were stable across all environments. Six QTLs
\end{abstract}

Communicated by F. Muehlbauer.

I. Schmalenbach $\cdot$ K. Pillen

Barley Genetics Research Group, Max Planck Institute for Plant

Breeding Research, Carl-von-Linné-Weg 10,

50829 Cologne, Germany

Present Address:

K. Pillen $(\square)$

Institute of Agricultural and Nutritional Sciences,

Martin-Luther-University Halle-Wittenberg,

Ludwig-Wucherer-Str. 2, 06108 Halle/Saale, Germany

e-mail: klaus.pillen@landw.uni-halle.de
$(15.0 \%)$ revealed a trait improving wild barley effect. Out of 36 QTLs detected in a previous advanced backcross QTL study with the parent $\mathrm{BC}_{2} \mathrm{DH}$ population $\mathrm{S} 42,18$ QTLs (50.0\%) could be verified with the S42IL set. For the quality parameters $\alpha$-amylase activity and Hartong $45^{\circ} \mathrm{C}$, all QTLs assessed in population S42 were verified by S42ILs. In addition, eight new QTL effects and 17 QTLs affecting two newly investigated traits were localized. Two QTL clusters harboring simultaneous effects on eight and six traits, respectively, were mapped to chromosomes $1 \mathrm{H}$ and $4 \mathrm{H}$. In future, fine-mapping of these QTL regions will be conducted in order to shed further light on the genetic basis of the most interesting QTLs.

\section{Introduction}

The most important end use of spring barley is the production of malt as substrate for brewing beer and distilling whisky. Malting quality is composed of numerous interacting traits with a high complexity concerning their biochemical and genetic basis (Fox et al. 2003). In most instances, the traits are conditioned by interaction of polygenes, so called quantitative trait loci (QTLs). To accelerate the breeding of cultivars with improved malting quality, molecular markers and genetic linkage maps were used to localize these loci. Thus, in recent years, the elite barley gene pool was extensively used for numerous QTL studies on malting quality (e.g. Marquez-Cedillo et al. 2000; See et al. 2002; Barr et al. 2003a, b; Collins et al. 2003; Emebiri et al. 2003, 2004, 2005; Hayes et al. 2003; Edney and Mather 2004; Rae et al. 2007; Panozzo et al. 2007).

The value of exotic barley germplasm as a source for trait improving alleles was proven by studies targeting 
quantitative traits. Although potentially useful allelic variation regarding important malting quality characteristics was identified in wild barley (Ahokas and Naskali 1990a, b; Zhang et al. 2007), the utilization of unadapted germplasm is, so far, restricted to a limited number of malting quality QTL studies. By means of "advanced backcross" (AB)-QTL studies with germplasm of the wild barley form Hordeum vulgare ssp. spontaneum, hereafter abbreviated with $H s p$ Pillen et al. (2003, 2004) and Li et al. (2005) detected putative QTLs affecting the parameters friability, protein content, water absorption and malt extract. A further AB-QTL study involving the same Hordeum subspecies as exotic parent was performed by von Korff et al. (2008). Here, $301 \mathrm{BC}_{2} \mathrm{DH}$ lines of the population $\mathrm{S} 42$ ('Scarlett' $\times$ 'ISR 42-8') were genotyped with 98 SSR markers, and, in addition, subjected to a micro malting experiment. Subsequently, the performance of the lines regarding seven malting quality characteristics (e.g. $\alpha$-amylase activity, fermentability, grain protein content and viscosity) was evaluated. By means of a mixed model analysis of variance, altogether 48 putative QTLs were assessed. At 18 QTLs (37.5\%), the exotic allele caused an improved trait performance.

Once QTLs influencing important traits are localized, this information can be exerted for further studies, for instance to investigate gene by gene and gene by environment interactions, pleiotropic effects and to map-based clone strong QTL effects. It is furthermore advisable to transfer favorable exotic QTL alleles into existing varieties, and, thus, to breed improved cultivars. Zamir (2001) recommended the use of introgression libraries for those applications. Each introgression line (IL) within such a library contains a single marker-defined chromosomal fragment of an exotic species, whereas the remaining part of the genome originates from an elite variety. A complete IL library, developed by several rounds of backcrossing and selfing and in parallel marker-assisted selection (MAS), represents the whole donor genome in overlapping introgressions. The great advantage of such an IL set compared to commonly used QTL mapping populations is the low proportion of exotic germplasm present in each line. Thereby, negative effects of donor alleles, i.e. linkage drag, are reduced and the phenotypic variation between the ILs can be attributed with high accuracy to the particular introduced segment. Due to their homozygosity, ILs are a stable resource which can be exerted for a multitude of purposes. Regarding end use quality, introgression libraries were so far evaluated in tomato (Rousseaux et al. 2005), rice (Zheng et al. 2007), wheat (Liu et al. 2007), melon (Eduardo et al. 2007; Fernandez-Trujillo et al. 2007; Obando et al. 2008), and rye (Falke et al. 2008). In barley, Matus et al. (2003) developed a set of 140 recombinant chromosome substitution lines (RCSLs) which contained in most instances multiple exotic segments of the exotic accession 'Caesarea 26-24'. By association analysis, the trait performance of the RCSLs was evaluated. Matus et al. (2003) observed significant transgressive segregation, and identified several QTL regions for the malting quality parameters $\alpha$-amylase activity, diastatic power, grain protein content, malt extract and wort $\beta$-glucan content. Furthermore, a set of $59 \mathrm{ILs}$, each harboring a single wild barley introgression in the uniform genetic background of elite barley, was selected and subsequently used for the verification of QTLs affecting disease resistance and agronomic performance (Schmalenbach et al. 2008, 2009).

The present paper reports on the application of a set of 39 wild barley introgression lines (S24ILs), taken from Schmalenbach et al. (2008), to conduct a malting quality QTL analysis. Each line harbors one single introgression of the exotic barley accession 'ISR 42-8' (Hsp) in the genetic background of the elite barley cultivar 'Scarlett' (Hordeum vulgare ssp. vulgare, hereafter abbreviated with $H v$ ). For evaluating the malting quality performance of the S42ILs, a micro malting experiment with grain samples from field tests in three different environments was conducted. Subsequently, the resulting data for eight malting quality parameters were analyzed within a line $\times$ phenotype association study in order (1) to verify QTL effects previously localized in the population S42 which consists of $301 \mathrm{BC}_{2} \mathrm{DH}$ lines (von Korff et al. 2008), (2) to detect new QTLs, and (3) to identify S42ILs exhibiting significant effects on several traits simultaneously.

\section{Materials and methods}

\section{Plant material}

Altogether 39 selected wild barley introgression lines (named S42IL-101 to S42IL-139) were subjected to a malting quality analysis. The S42ILs were developed based on an initial cross between the German spring barley cultivar 'Scarlett' and the Israeli wild barley accession 'ISR 42-8'. Subsequently, three rounds of backcrossing with the recurrent parent, repeated selfing and, in parallel, marker-assisted selection (MAS) were conducted. Finally, the S42ILs were selected in $\mathrm{BC}_{3} \mathrm{~S}_{2}$ or $\mathrm{BC}_{3} \mathrm{~S}_{4}$ generation. Each S42IL harbors a single SSR marker-defined chromosomal segment of the exotic parent, whereas the remaining genome is derived from the elite parent. The construction and genotypic characterization of the lines, as well as their application to verify QTL effects for disease resistances, are described in detail in Schmalenbach et al. (2008). 
Field cultivation of the introgression lines

The 39 S42ILs were cultivated at three different locations in Germany during the season 2007 to evaluate agronomic performance (Schmalenbach et al. 2009) and to obtain seed material for micro malting. The locations were the experimental research station Dikopshof (D07, University of Bonn, western Germany), and the breeders' experimental field stations in Gudow (G07, Nordsaat Saatzucht, northern Germany) and Herzogenaurach (H07, Saatzucht Josef Breun, southeastern Germany). The introgression lines were grown in three replications (blocks) per location. As a control, the elite parent 'Scarlett' was tested in four replications per block. Growing conditions such as net plot sizes $\left(4.5-6.0 \mathrm{~m}^{2}\right)$, seed density $\left(300-390 \mathrm{kernels} / \mathrm{m}^{2}\right)$, nitrogen fertilization (30-80 kg N/ha) and field management followed local practice. Further details are given in Schmalenbach et al. (2009).

Malting quality analysis

Micro malting and malting quality analysis were conducted in the laboratory of Nordsaat Saatzucht (Böhnshausen, Germany), using $100 \mathrm{~g}$ of grain of the sieving fraction $>2.5 \mathrm{~mm}$. The malting process and the determination of $\alpha$-amylase activity and raw protein content were performed as described in von Korff et al. (2008). Both traits as well as the quality characters fine-grind extract of malt, friability of malt, and viscosity of wort were measured using the methods recommended by the European Brewery Convention (EBC). The traits Kolbach index and Hartong $45^{\circ} \mathrm{C}$ were determined according to the methods of the Mitteleuropäische Brautechnische Analysenkommission (MEBAK). The investigated traits are explained in Table 1. The exotic parent 'ISR 42-8' was not included in the experiment since, in general, wild barley exhibits no malting quality, and, in addition, sufficient number of seeds for micro malting was not available.

\section{Statistical analyzes}

Statistical analyzes were performed with SAS Enterprise Guide 4.1 (SAS Institute 2006). Genetic correlations between trait values were determined with the least squares means (LSMEANS) for each of the 39 S42ILs averaged across all replications and environments. The LSMEANS were computed with the general linear model (GLM) procedure and used for calculating Pearson's correlation coefficient $(r)$ with the CORR procedure.

For identification and verification of QTL effects, the phenotype data of the S42ILs was subjected to a line $\mathrm{x}$ phenotype association study. First, the following two-factorial mixed model analysis of variance (ANOVA) was carried out with the GLM procedure:

$Y_{i j k}=\mu+L_{i}+E_{j}+L \times E_{i j}+\varepsilon_{k(i j)}$,

where $\mu$ is the general mean, $L_{i}$ is the fixed effect of the $i$ th line, $E_{j}$ is the random effect of the $j$ th environment, $L \times E_{i j}$ is the random interaction effect of the $i$ th line and the $j$ th environment, and $\varepsilon_{k(i j)}$ is the error of $Y_{i j k}$.

When the analysis revealed significant $(P<0.05)$ differences between lines or line $\mathrm{x}$ environment interactions, a Dunnett test was conducted (Dunnett 1955). Here, the LSMEANS of each S42IL and of 'Scarlett' as a control were tested for significant differences. When the LSMEANS of a particular S42IL was significantly $(P<0.05)$ different from 'Scarlett' across all three environments and/or in a particular environment, the presence of a QTL was assumed. It was detected either as line main effect or as line $\times$ environment interaction effect or as

Table 1 List of eight malting quality traits evaluated for 39 S42ILs in three environments

\begin{tabular}{|c|c|c|c|c|}
\hline Abbr. & Trait & Units & $\begin{array}{l}\text { Reference/method of } \\
\text { measurement }\end{array}$ & Breeding goal $^{\mathrm{b}}$ \\
\hline AA & $\alpha$-amylase activity of malt & Dextrinizing units (DU) & EBC 4.13 & + \\
\hline FGE & Fine-grind extract of malt & $\%$ dry mass & EBC 4.5.1 & + \\
\hline FRI & Friability of malt & $\%$ & EBC 4.15 & + \\
\hline GPC & Grain protein content & $\%$ dry mass & EBC 3.3 .1 & - \\
\hline GSF & Grain sieving fraction $>2.5 \mathrm{~mm}$ & $\%$ & MEBAK 2.3 .1 & + \\
\hline KOL & $\begin{array}{l}\text { Kolbach index (soluble protein/ } \\
\text { total protein ratio) }\end{array}$ & $\%$ & $\begin{array}{l}\text { MEBAK I 4.1.4.5.2 (soluble } \\
\text { protein), MEBAK I 4.1.4.5.3 } \\
\text { (Kolbach index) }\end{array}$ & + \\
\hline VIS & Viscosity of wort & mPas & EBC 4.8 & - \\
\hline VZ45 & Hartong $45^{\circ} \mathrm{C}$, extract at $45^{\circ} \mathrm{C}$ & $\%$ & MEBAK I 4.1.4.11 & + \\
\hline
\end{tabular}

\footnotetext{
${ }^{a}$ EBC and MEBAK: see reference list
}

b The breeding goals are defined in order to select improved malting barley, where (-) indicates that a reduction, and $(+)$ that an increase of the trait is desired 
both effects simultaneously. If several lines, which carry overlapping or flanking introgressions, revealed a significant effect of the same direction (increase or reduction of trait value), it was assumed that these lines harbored the same QTL. Introgressions do overlap, if they possess at least one common $H s p$ allele. They flank each other, if they have adjacent $H s p$ alleles. The relative performance of a particular S42IL was calculated as follows: RP $[\mathrm{S} 42 \mathrm{IL}]=\left(\right.$ LSMEANS $[\mathrm{S} 42 \mathrm{IL}]-$ LSMEANS $\quad\left[{ }^{\prime}\right.$ Scarlett'])*100/LSMEANS ['Scarlett'], where for each trait the LSMEANS were calculated across all replications and environments.

\section{Data storage}

For general use, all genotype and phenotype data of the S42IL set will be archived in the public IL data base 'Phenom Networks' (http://phn.huji.ac.il/RTQ/).

\section{Results}

Trait performances of 'Scarlett' and the S42IL set

In Table 2, the parameters mean, minimum, maximum, and coefficient of variation specify the performance of the recurrent parent 'Scarlett' and the S42IL set for each trait. The values are indicated per environment and across all three environments. For all traits and environments, except for grain protein content in environment D07, the S42ILs revealed a higher coefficient of variation than 'Scarlett'. Across all environments, the recurrent parent as well as the S42ILs, exhibited the highest coefficient of variation for the traits $\alpha$-amylase activity (22.0 and $22.1 \%$, respectively) and grain sieving fraction $>2.5 \mathrm{~mm}$ (13.6 and $14.9 \%$, respectively). Low variation in performance was assessed for fine-grind extract, viscosity and grain protein content. For almost all traits and environments 'Scarlett' showed a higher average performance than the S42IL set. As listed in Table 2, an exception is grain protein content where the mean is slightly lower for the recurrent parent than the S42ILs in each environment. The same observation was detected for viscosity in environments D07 and G07.

Genetic correlations

Altogether 27 significant correlations were assessed between the eight investigated parameters (Table 3). Solely $\alpha$-amylase activity and fine-grind extract showed no significant correlation. Twenty-two genetic correlations were highly significant $(P<0.001)$. Strong positive correlations were detected between VZ45 and the traits Kolbach index, $\alpha$-amylase activity and friability $(r=0.92,0.83$ and 0.73 , respectively). The latter two traits were also highly positively correlated with Kolbach index $(r=0.86$ and 0.82 , respectively) and among each other $(r=0.69)$. Finally, a strong positive correlation of 0.73 was measured between grain sieving fraction $>2.5 \mathrm{~mm}$ and viscosity. Grain protein content revealed negative correlations with friability, Kolbach index, Hartong $45^{\circ} \mathrm{C}$, fine-grind extract and $\alpha$-amylase activity $(r=-0.69,-0.69,-0.67,-0.52$ and -0.44 , respectively). In addition, friability and Kolbach index exhibited negative correlations of -0.64 and -0.59 , respectively, with viscosity which was also negatively correlated with $\alpha$-amylase activity $(r=-0.55)$. The trait grain sieving fraction $>2.5 \mathrm{~mm}$ correlated negatively to Kolbach index, $\alpha$-amylase activity, friability and Hartong $45^{\circ} \mathrm{C}$ ( $r=-0.60,-0.55,-0.48$ and -0.46 respectively), but positively to fine-grind extract and grain protein content ( $r=0.46$ and 0.22 , respectively).

\section{Detection of QTL effects}

In order to assess QTL effects on malting quality, the 39 S42ILs were subjected to a line $\mathrm{x}$ phenotype association study. For all eight investigated traits, the two-factorial mixed model ANOVA revealed significant line effects $(P<0.05)$. Significant line $x$ environment interactions $(P<0.05)$ were detected for all traits with the exception of fine-grind extract and viscosity (data not shown).

As presented in Table 4, altogether 68 significant line $\times$ phenotype associations were exhibited by the subsequently performed Dunnett test. For 45 associations, both, the line main effect and the line $\times$ environment interaction effect were significant, whereas for eleven associations solely the line main effect was significant. The remaining 12 associations were detected solely as line $x$ environment interaction effect. Due to the overlapping or flanking of several introgressions, the associations were summarized to a total of 40 QTLs. At 30 QTLs the line main as well as the line $\mathrm{x}$ environment interaction effect was significant. At six out of the 40 QTLs (15.0\%), the exotic introgression was associated with an improved trait performance compared to the control 'Scarlett'. Those favorable Hsp effects were detected for the traits $\alpha$-amylase activity, grain sieving fraction $>2.5 \mathrm{~mm}$ and Kolbach index. In the following, the detected QTL effects are specified for each trait separately (see Table 4).

$\alpha$-amylase activity (AA)

For AA, altogether ten S42ILs on all chromosomes except $2 \mathrm{H}$ and $3 \mathrm{H}$ exhibited a significant line $\mathrm{x}$ phenotype association, among which four lines harbor an exotic segment on chromosome $1 \mathrm{H}$. Taking into account that some lines carry 
Table 2 Parameters describing the trait performance of the recurrent parent 'Scarlett' and the S42ILs per environment and across all tested environments

\begin{tabular}{|c|c|c|c|c|c|c|c|c|c|c|}
\hline \multirow[t]{2}{*}{ Trait and environment ${ }^{\mathrm{a}}$} & \multicolumn{5}{|c|}{ 'Scarlett' } & \multicolumn{5}{|c|}{ S42ILs } \\
\hline & $N^{\mathrm{b}}$ & $\operatorname{Mean}^{\mathrm{c}}$ & $\operatorname{Min}^{\mathrm{d}}$ & $\operatorname{Max}^{\mathrm{d}}$ & $\mathrm{CV}^{\mathrm{e}}$ & $N^{\mathrm{b}}$ & Mean $^{c}$ & $\operatorname{Min}^{\mathrm{d}}$ & $\operatorname{Max}^{\mathrm{d}}$ & $\mathrm{CV}^{\mathrm{e}}$ \\
\hline \multicolumn{11}{|l|}{$\mathrm{AA}$} \\
\hline D07 & 12 & 382.8 & 355.0 & 439.0 & 7.8 & 117 & 377.4 & 203.0 & 513.0 & 17.4 \\
\hline G07 & 12 & 411.5 & 338.0 & 522.0 & 14.1 & 117 & 394.9 & 258.0 & 561.0 & 16.9 \\
\hline $\mathrm{H} 07$ & 12 & 572.3 & 481.0 & 691.0 & 12.1 & 117 & 527.0 & 361.0 & 734.0 & 13.9 \\
\hline Across all env. & 36 & 455.6 & 338.0 & 691.0 & 22.0 & 351 & 433.1 & 203.0 & 734.0 & 22.1 \\
\hline \multicolumn{11}{|l|}{ FGE } \\
\hline D07 & 12 & 81.0 & 79.8 & 82.3 & 0.9 & 117 & 80.4 & 77.8 & 82.5 & 1.1 \\
\hline G07 & 12 & 82.4 & 80.7 & 84.2 & 1.2 & 117 & 81.6 & 78.9 & 85.3 & 1.5 \\
\hline H07 & 12 & 81.8 & 80.2 & 84.3 & 1.5 & 117 & 80.8 & 77.7 & 83.4 & 1.6 \\
\hline Across all env. & 36 & 81.7 & 79.8 & 84.3 & 1.4 & 351 & 80.9 & 77.7 & 85.3 & 1.6 \\
\hline \multicolumn{11}{|l|}{ FRI } \\
\hline D07 & 12 & 71.6 & 61.0 & 83.0 & 8.9 & 117 & 67.9 & 48.0 & 86.0 & 11.7 \\
\hline G07 & 12 & 70.0 & 62.0 & 83.0 & 8.3 & 117 & 68.0 & 45.0 & 86.0 & 11.0 \\
\hline H07 & 12 & 81.0 & 73.0 & 91.0 & 6.3 & 117 & 80.2 & 59.0 & 94.0 & 8.6 \\
\hline Across all env. & 36 & 74.2 & 61.0 & 91.0 & 10.1 & 351 & 72.0 & 45.0 & 94.0 & 13.1 \\
\hline \multicolumn{11}{|l|}{ GPC } \\
\hline D07 & 12 & 12.4 & 11.7 & 13.1 & 3.9 & 117 & 12.5 & 11.7 & 13.7 & 3.4 \\
\hline G07 & 12 & 11.9 & 11.4 & 12.5 & 2.6 & 117 & 12.1 & 10.8 & 13.7 & 5.0 \\
\hline H07 & 12 & 11.5 & 10.7 & 12.5 & 5.2 & 117 & 11.6 & 10.0 & 13.0 & 5.4 \\
\hline Across all env. & 36 & 11.9 & 10.7 & 13.1 & 4.9 & 351 & 12.1 & 10.0 & 13.7 & 5.6 \\
\hline \multicolumn{11}{|l|}{ GSF } \\
\hline D07 & 12 & 81.1 & 72.3 & 87.4 & 4.6 & 117 & 77.7 & 64.5 & 89.9 & 7.3 \\
\hline G07 & 12 & 91.3 & 88.5 & 93.0 & 1.6 & 117 & 89.9 & 73.1 & 96.4 & 4.8 \\
\hline $\mathrm{H} 07$ & 12 & 66.6 & 60.6 & 77.2 & 6.7 & 117 & 65.6 & 47.9 & 86.1 & 11.5 \\
\hline Across all env. & 36 & 79.7 & 60.6 & 93.0 & 13.6 & 351 & 77.7 & 47.9 & 96.4 & 14.9 \\
\hline \multicolumn{11}{|l|}{ KOL } \\
\hline D07 & 12 & 41.7 & 40.0 & 43.3 & 2.3 & 117 & 40.2 & 34.0 & 45.0 & 5.4 \\
\hline G07 & 12 & 42.0 & 39.5 & 43.7 & 3.0 & 117 & 41.2 & 35.7 & 46.8 & 5.2 \\
\hline H07 & 12 & 48.7 & 45.6 & 51.6 & 3.0 & 117 & 48.1 & 40.7 & 54.1 & 5.9 \\
\hline Across all env. & 36 & 44.1 & 39.5 & 51.6 & 7.9 & 351 & 43.2 & 34.0 & 54.1 & 9.8 \\
\hline \multicolumn{11}{|l|}{ VIS } \\
\hline D07 & 12 & 1.46 & 1.43 & 1.50 & 1.6 & 117 & 1.47 & 1.41 & 1.61 & 2.5 \\
\hline G07 & 12 & 1.54 & 1.51 & 1.59 & 1.6 & 117 & 1.55 & 1.48 & 1.72 & 3.0 \\
\hline H07 & 12 & 1.44 & 1.41 & 1.47 & 1.6 & 117 & 1.43 & 1.39 & 1.53 & 1.9 \\
\hline Across all env. & 36 & 1.48 & 1.41 & 1.59 & 3.4 & 351 & 1.48 & 1.39 & 1.72 & 4.2 \\
\hline \multicolumn{11}{|l|}{ VZ45 } \\
\hline D07 & 12 & 42.0 & 38.6 & 43.8 & 3.7 & 117 & 40.5 & 34.7 & 46.8 & 6.8 \\
\hline G07 & 12 & 46.1 & 43.4 & 49.4 & 3.5 & 117 & 46.0 & 39.5 & 54.3 & 6.6 \\
\hline $\mathrm{H} 07$ & 12 & 55.3 & 51.8 & 58.5 & 3.1 & 117 & 54.0 & 45.6 & 62.0 & 6.9 \\
\hline Across all env. & 36 & 47.8 & 38.6 & 58.5 & 12.2 & 351 & 46.8 & 34.7 & 62.0 & 13.7 \\
\hline
\end{tabular}

\footnotetext{
a Trait and environment abbreviations are listed in Table 1 and "Materials and methods", respectively

b Number of observations

c Average trait performance

d Minimum and maximum trait performance

${ }^{\mathrm{e}}$ Coefficient of variation
} 
Table 3 Pearson correlation coefficients $(r)$ between eight malting quality traits in 39 S42ILs

\begin{tabular}{|c|c|c|c|c|c|c|c|}
\hline Traits & FGE & FRI & GPC & GSF & KOL & VIS & VZ45 \\
\hline AA & 0.06 & $0.69 * * *$ & $-0.44 * * *$ & $-0.55 * * *$ & $0.86^{* * *}$ & $-0.55 * * *$ & $0.83 * * *$ \\
\hline FGE & & $0.30 * * *$ & $-0.52 * * *$ & $0.46 * * *$ & $0.18^{*}$ & $0.22 *$ & $0.25 * *$ \\
\hline FRI & & & $-0.69 * * *$ & $-0.48 * * *$ & $0.82 * * *$ & $-0.64 * * *$ & $0.73 * * *$ \\
\hline GPC & & & & $0.22 *$ & $-0.69 * * *$ & $0.18^{*}$ & $-0.67 * * *$ \\
\hline GSF & & & & & $-0.60 * * *$ & $0.73 * * *$ & $-0.46 * * *$ \\
\hline KOL & & & & & & $-0.59 * * *$ & $0.92 * * *$ \\
\hline VIS & & & & & & & $-0.37 * * *$ \\
\hline
\end{tabular}

The malting quality traits are defined in Table 1 . For calculating correlation coefficients, the least squares means of the trait performance of each IL were averaged across replications and environments. The $r$ values are significant with $* P<0.05, * * P<0.01$ or $* * * P<0.001$

overlapping or flanking $H s p$ segments, the associations were summarized to seven putative QTLs, among which five QTLs revealed a significant line main and line $\times$ environment interaction effect simultaneously. At two QTLs on chromosome 4H, QAa.S42IL-4H.a and QAa.S42IL-4H.b, a favorable $H s p$ effect was detected. Here, the $\alpha$-amylase activity of the S42ILs -116 and -124 was enhanced by 20.0 and $16.2 \%$, respectively, relative to the recurrent parent 'Scarlett'. A maximum reduction of trait performance of $-32.5 \%$ was measured at QAa.S42IL-5H.a for S42IL-125 containing an exotic introgression in the region $5 \mathrm{H}$, 43-69 cM (Table 4).

\section{Fine-grind extract (FGE)}

A total of seven significant line $\times$ phenotype associations on chromosomes $1 \mathrm{H}, 4 \mathrm{H}, 6 \mathrm{H}$ and $7 \mathrm{H}$, summarized to four QTL effects, were detected for FGE. At all QTLs, both, the line main and the line $\times$ environment interaction effect were significant, and the $H s p$ introgression was associated with a decreased FGE compared to 'Scarlett'. The highest differences between the performance of an IL and the control were exhibited at QFge.S42IL-1H.a for S42IL-102 and -103 , containing $H s p$ introgressions within the region $1 \mathrm{H}, 0-85 \mathrm{cM}$ and $1 \mathrm{H}, 39-70 \mathrm{cM}$, respectively $(-3.2$ and $-2.9 \%$, respectively).

\section{Friability (FRI)}

For FRI, six significant line $\times$ phenotype associations were detected on chromosomes $1 \mathrm{H}$ and $4 \mathrm{H}$. In two cases, represented by S42ILs -118 and -119 , the effect was solely significant in environment D07 (Table 4). The six significant associations could be summarized to two QTL effects. The exotic introgression reduced the trait value by a maximum of $-20.0 \%$ in S42IL-102, carrying a $H s p$ segment in the chromosomal region $1 \mathrm{H}$, $0-85 \mathrm{cM}$.
Grain protein content (GPC)

For GPC, six significant line $\times$ phenotype associations, summarized to four putative QTLs, were identified on chromosomes $1 \mathrm{H}, 4 \mathrm{H}, 6 \mathrm{H}$ and $7 \mathrm{H}$. Five associations showed both, a significant line main and a line $\times$ environment interaction effect, whereas S42IL-128 exhibited solely a significant line main effect. At QGpc.S42IL-6H.a the $H s p$ segment of S42IL-129, present in the region $6 \mathrm{H}$, 96-112 cM, caused a maximum increase of GPC of $8.9 \%$, relative to the control. Other strong exotic increasing effects were measured at QGpc.S42IL-4H.a and QGpc.S42IL-7H.a (7.7 and 7.4\%, respectively).

\section{Grain sieving fraction $>2.5 \mathrm{~mm}(\mathrm{GSF})$}

Seventeen significant line $\times$ phenotype associations were identified for GSF on all chromosomes with the exception of $5 \mathrm{H}$ and $6 \mathrm{H}$. Due to the overlapping or flanking of several introgressions, a total of ten putative QTLs were identified, among which three QTLs each were mapped to chromosomes $2 \mathrm{H}$ and $4 \mathrm{H}$. At seven loci the line main and the line $\mathrm{x}$ environment interaction effect were significant. In contrast, two QTLs were solely detected as line main effects, and one QTL (QGsf.S42IL-3H.a) only as interaction effect in environment D07. At QGsf.S42IL-2H.a, QGsf.S42IL2H.c and QGsf.S42IL-4H.a, the exotic introgression caused a favorable increase of GSF by 8.4, 6.7 and 6.2\%, respectively. The strongest unfavorable effect on GSF was exhibited by S42IL-122, carrying an Hsp segment on chromosome $4 \mathrm{H}, 125-132 \mathrm{cM}$. Here, the trait performance was reduced by $14.1 \%$.

Kolbach index (KOL)

Altogether eleven S42ILs on all chromosomes except $2 \mathrm{H}$ revealed a significant line $\mathrm{x}$ phenotype association for KOL. Due to the overlapping or flanking of several 


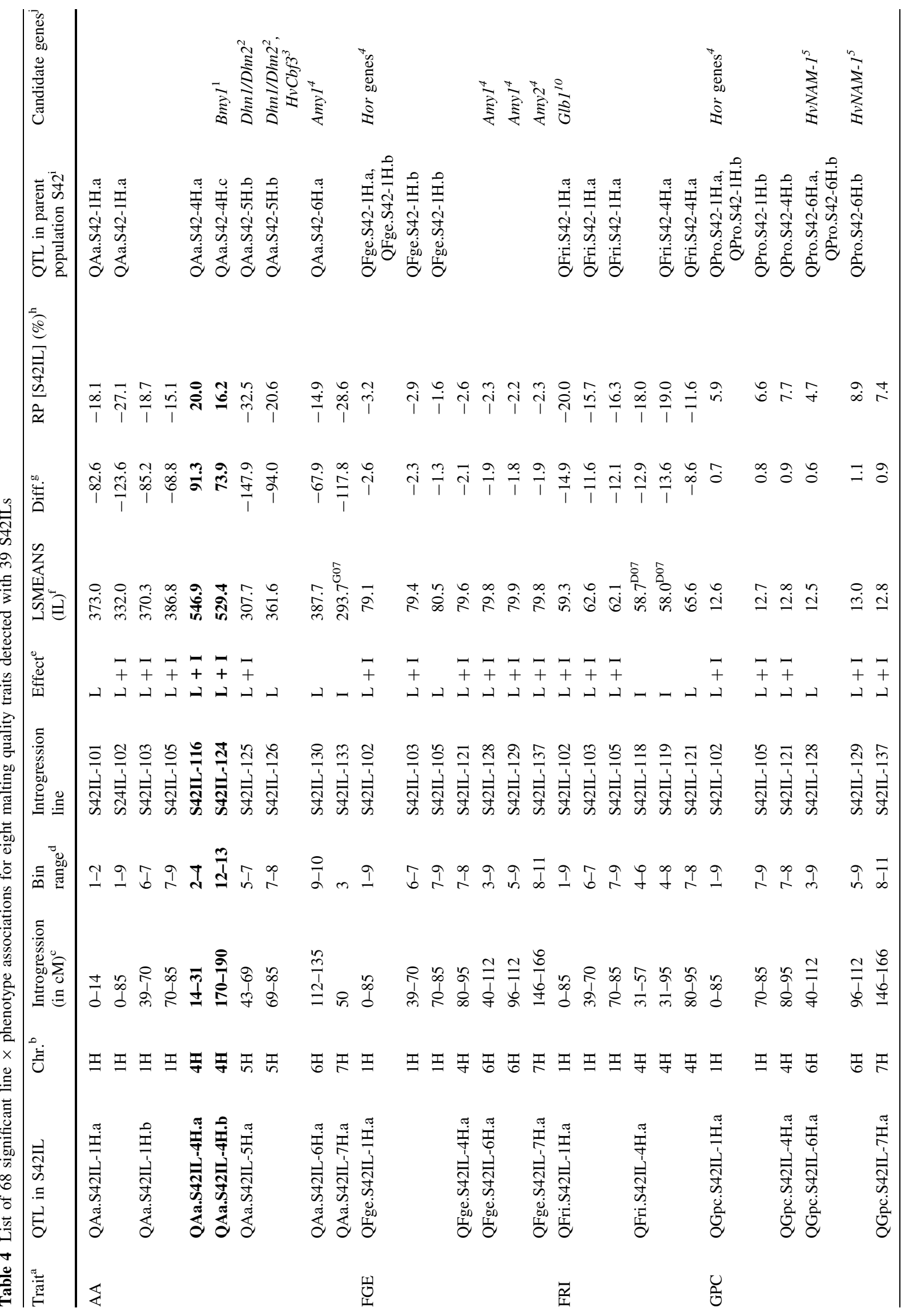




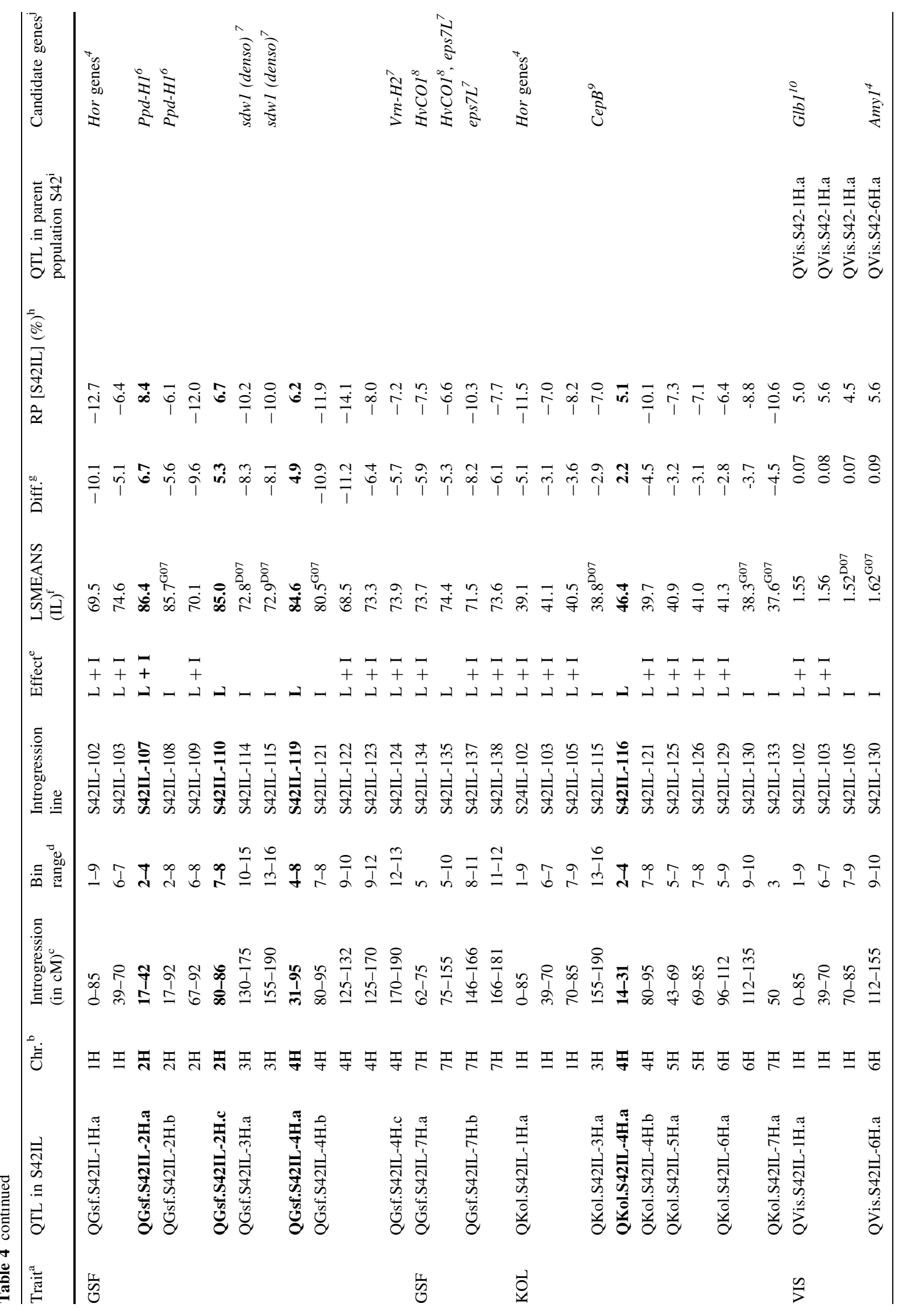







introgressions, they were summarized to seven QTL effects, among which four effects were detected as significant line main and line $\mathrm{x}$ environment interaction effect, simultaneously. In contrast, at QKol.S42IL-3H.a and QKol.S42IL-7H.a solely the line $\times$ environment interaction effect was significant, whereas at QKol.S42IL-4H.a only the line main effect was significant. Here, the exotic introgression, located within the region $4 \mathrm{H}, 14-31 \mathrm{cM}$, increased KOL by $5.1 \%$, relative to the control. The strongest reduction effects were mapped to the regions $1 \mathrm{H}$, $0-85 \mathrm{cM}$ and $7 \mathrm{H}, 50 \mathrm{cM}$ by S42IL-102 and -133 , respectively. Here, the trait value was decreased by 11.5 and $10.6 \%$, respectively, relative to 'Scarlett'.

\section{Viscosity (VIS)}

Four significant line $\times$ phenotype associations, summarized to two QTL effects, were identified for VIS on chromosomes $1 \mathrm{H}$ and $6 \mathrm{H}$. The strongest $H s p$ effect was mapped to the chromosomal regions $1 \mathrm{H}, 39-70 \mathrm{cM}$ and $6 \mathrm{H}, 112-155 \mathrm{cM}$ by the S42ILs-103 and -130, respectively. Both lines revealed a viscosity increased by $5.6 \%$, relative to 'Scarlett' (Table 4). At QVis.S42IL-6H.a, this effect was only significant in environment G07.

\section{Hartong $45^{\circ} \mathrm{C}(\mathrm{VZ45})$}

A total of seven significant line $\times$ phenotype associations were detected for VZ45 on chromosomes $1 \mathrm{H}, 4 \mathrm{H}, 5 \mathrm{H}$ and $6 \mathrm{H}$. These associations were summarized to four QTL effects. At three QTLs, the line main effect as well as the line $\times$ environment interaction effect was significant, whereas QVZ45.S42IL-6H.a was solely detected as line main effect. At QVZ45.S42IL-1H.a, the exotic introgression, localized in the region $1 \mathrm{H}, 39-70 \mathrm{cM}$, was associated with a trait performance decreased by $10.5 \%$, relative to the recurrent parent. Further strong reduction effects were mapped to the regions $5 \mathrm{H}, 43-69 \mathrm{cM}$ and $1 \mathrm{H}, 0-85 \mathrm{cM}$ by S42IL-125 and -102 , respectively $(-10.1$ and $-9.8 \%$, respectively).

\section{Discussion}

Detection and verification of QTL effects

The objectives of this study were (1) to verify QTLs affecting malting quality parameters which were previously detected within the parent population S42 (von Korff et al. 2008), (2) to identify new QTLs, and (3) to assess S42ILs revealing multiple QTL effects.

By association analysis, altogether 68 significant line $\times$ phenotype associations, summarized to 40 putative
QTLs, were identified using the S42IL set. Since only at six out of 40 QTLs $(15.0 \%)$ the exotic introgression was associated with an improved trait performance, a strong selection on favorable malting quality alleles during the breeding process can be assumed. This observation is in contrast to a previous QTL study where the agronomic performance of the S42IL set was evaluated. In the latter case, a high portion of the detected QTLs $(40.4 \%)$ for yield related traits revealed a favorable $H s p$ effect (Schmalenbach et al. 2009). This discrepancy possibly indicates that the selective breeding for malting quality might have been stronger than for agronomic performance. Alternatively, the genetic diversity in exotic barley might be higher for agronomic parameters than for malting quality.

The six traits AA, FGE, FRI, GPC, VIS and VZ45 were investigated within the S42ILs as well as in the parent population S42. In addition, the S42ILs were evaluated with regard to GSF and KOL. In population S42, von Korff et al. (2008) identified a total of 45 putative QTLs for the six corresponding traits, among which one-third showed a favorable effect of the exotic allele. Thirty-six out of the 45 QTLs (80.0\%) are located in chromosomal regions which are represented by $H s p$ segments in S42ILs. Hence, these 36 QTL effects are comparable with QTLs detected in the S42IL set. To enable the verification of the remaining QTLs of population S42, introgression lines carrying the donor allele in these regions are currently under construction and will in future be subjected to malting quality analysis. As listed in Table 4, half of the 36 QTLs of the parent population S42 were confirmed by the evaluated S42ILs. For the traits AA and VZ45 all QTLs except one were verified, whereas for VIS and FRI two out of seven QTLs (28.6\%) were confirmed. At 15 out of the 18 verified QTLs (83.3\%), an $H s p$ effect of the same direction, i.e. either an increase or a reduction of the trait value caused by the exotic genotype, was measured in both populations. For 12 out of these 15 consistent QTLs (80.0\%), at least one S42IL revealed a higher relative trait performance in comparison to the control 'Scarlett' than assessed for the corresponding QTL in population S42 (see also von Korff et al. 2008).

For traits AA, FGE, GPC and VZ45, altogether eight new QTL effects, previously not assessed in population S42, were identified in the S42IL set. All these QTLs exhibited an unfavorable $H s p$ effect. In addition, a total of 17 QTLs affecting the newly investigated traits GSF or KOL were mapped by S42ILs. At four QTLs (23.5\%), the exotic introgression was associated with a favorable increase of the trait value compared to 'Scarlett'.

Inconsistent results of the two compared studies might be explained by different hypotheses. It could be that interactions between non-linked $H s p$ alleles, present in the S42 population, are no more existent in the S42ILs. Since 
the S42ILs carry single exotic segments, whereas the $\mathrm{BC}_{2} \mathrm{DH}$ lines of population $\mathrm{S} 42$ contain several independent introgressions, potential epistatic effects are expected to be reduced in the S42ILs. Furthermore, contradictory results of the two compared studies might be attributed to genotype $\mathrm{x}$ environment interactions.

In the following, the QTL results of the present study are discussed in detail. They are compared to significant effects, detected in population S42 (von Korff et al. 2008) and in other malting quality QTL studies, and are related to possible candidate genes which are located in the same chromosomal region.

\section{$\alpha$-amylase activity}

In population S42 von Korff et al. (2008) detected six putative QTLs which map to chromosomal regions represented by exotic introgressions of S42ILs. All these QTLs, with the exception of QAa.S42-4H.b, were confirmed by S42ILs, and at four out of the five verified QTLs an effect with the same direction was assessed in both populations. In contrast, at QAa.S42IL-6H.a/ QAa.S42-6H.a the $H s p$ genotype caused a decrease of AA in S42IL-130, but a favorable increase in population S42 ( -14.9 and $16.0 \%$ relative to 'Scarlett', respectively). Two favorable exotic QTL effects, stable across all tested environments in both populations, were localized on chromosome $4 \mathrm{H}$ (Table 4 ). Here, $\alpha$-amylase activity was enhanced by a maximum of $20.0 \%$ at QAa.S42IL-4H.a in S42IL-116, and by $16.3 \%$ at QAa.S42-4H.c in population S42. The region 4H, 170-190 cM, harboring QAa.S42IL4H.b and QAa.S42-4H.c, corresponds to the locus of Bmyl, coding for $\beta$-amylase (Clark et al. 2003). Different hypotheses, possibly explaining the association between QTLs for $\alpha$-amylase activity and Bmyl are discussed by von Korff et al. (2008). For instance, it could be assumed that this gene might have a pleiotropic effect. In both studies compared, the strongest unfavorable $H s p$ effect, stable across all environments, was mapped to the region 5H, 43-69 cM (QAa.S42IL-5H.a and QAa.S42-5H.b, respectively). Here, the exotic genotype was associated with an enzyme activity reduced by $-32.5 \%$ in S42IL125 and $-21.5 \%$ in population S42. Several stress related genes like Dhn1/Dhn2 (Choi et al. 2000) and $\mathrm{HvCbf3}$ (Choi et al. 2002) also map to this region on chromosome $5 \mathrm{H}$. They might be associated with a high thermostability of $\alpha$-amylase, and, thus, with a preserved enzyme activity during the mashing process. As shown in Table 4, a further decreasing $H s p$ effect on AA was identified in both populations in the chromosomal region $6 \mathrm{H}$, 112-135 cM, which coincides with Amyl encoding for one of the two known forms of $\alpha$-amylase (Rostoks et al. 2005).
As shown in Table 3, a strong positive genetic correlation of 0.86 was assessed between AA and KOL. This coincides with the co-localization of five QTLs on all chromosomes except $2 \mathrm{H}$ and $3 \mathrm{H}$, all revealing an $H s p$ effect of the same direction on both traits. Furthermore, two QTLs on chromosome $1 \mathrm{H}$ and $5 \mathrm{H}$ were associated with a reducing $H s p$ effect on AA as well as on VZ45. These consistent effects correspond to a positive correlation of 0.83 between both traits.

\section{Fine-grind extract and Hartong $45^{\circ} \mathrm{C}$}

For FGE, altogether four QTL effects were localized in population $\mathrm{S} 42$ on chromosomes $1 \mathrm{H}, 3 \mathrm{H}$ and $7 \mathrm{H}$. All QTLs are located within genomic regions which are covered by exotic introgressions of S42ILs. The two QTLs QFge.S421H.a and QFge.S42-1H.b were confirmed by QFge.S42IL$1 \mathrm{H} . \mathrm{a}$, which showed significant line $\times$ phenotype associations for S42ILs-102, -103 and -105 (Table 4). In this QTL region, a maximum reduction of trait performance caused by the $H s p$ genotype was assessed in population S42 as well as in the S42ILs $(-2.2$ and $-3.2 \%$, respectively). Furthermore, the QTLs were stable across all environments in both populations. In the same region, Thomas (2003) revealed a QTL "hot-spot" harboring QTLs for the malting parameter hot water extract from five different barley crosses.

In addition to the confirmed QTLs, altogether three new significant effects on FGE were identified on chromosomes $4 \mathrm{H}, 6 \mathrm{H}$ and $7 \mathrm{H}$ by S42ILs. The location of QFge.S42IL6H.a coincides with the Amyl locus (Rostoks et al. 2005) as well as with a second QTL cluster for hot water extract which was mapped on the 'Steptoe' $\times$ 'Morex' map (Thomas 2003). The locus of Amy2, coding for the second form of $\alpha$-amylase, corresponds to the newly identified QTL QFge.S42IL-7H.a (Rostoks et al. 2005).

In population S42, three putative QTLs affecting VZ45 were mapped to chromosomal regions which are already represented by S42ILs. Two QTL effects (66.7\%) were confirmed within the present study. In both populations, the exotic genotype caused a maximum decrease of VZ45 on the top of chromosome $1 \mathrm{H}(-9.1 \%$ at QVZ45.S42-1H.a and $-10.5 \%$ at QVZ45.S42IL-1H.a). Within the S42IL set, two new QTLs were localized in the regions $4 \mathrm{H}, 80-95 \mathrm{cM}$ and $6 \mathrm{H}, 40-112 \mathrm{cM}$. Both effects were stable across all three tested environments and exhibited an unfavorable $H s p$ effect.

In the present study, a low positive correlation between FGE and VZ45 was measured $(r=0.25)$. In contrast, the traits exhibited a strong positive correlation $(r=0.58)$ in population S42 (von Korff et al. 2008) which was expected since both parameters characterize the activity of cytolytic and proteolytic malt enzymes, and, thus, are closely linked. 
Fig. 1 SSR map with 68 significant $(P<0.05)$ line $\times$ trait associations for 39 S42ILs and eight malting quality traits. The chromosomes are shown as black bars with $\mathrm{cM}$ values for SSR loci following the order of von Korff et al. (2004). The extent of $H s p$ introgressions are given in grey bars right to the chromosomes.

The associations are illustrated as symbols below the S42ILs.

They either reveal a favorable (filled symbols) or unfavorable (empty symbols) Hsp effect. Associations solely detected as line $\mathrm{x}$ environment interaction effect are marked by an asterisk right to the symbol
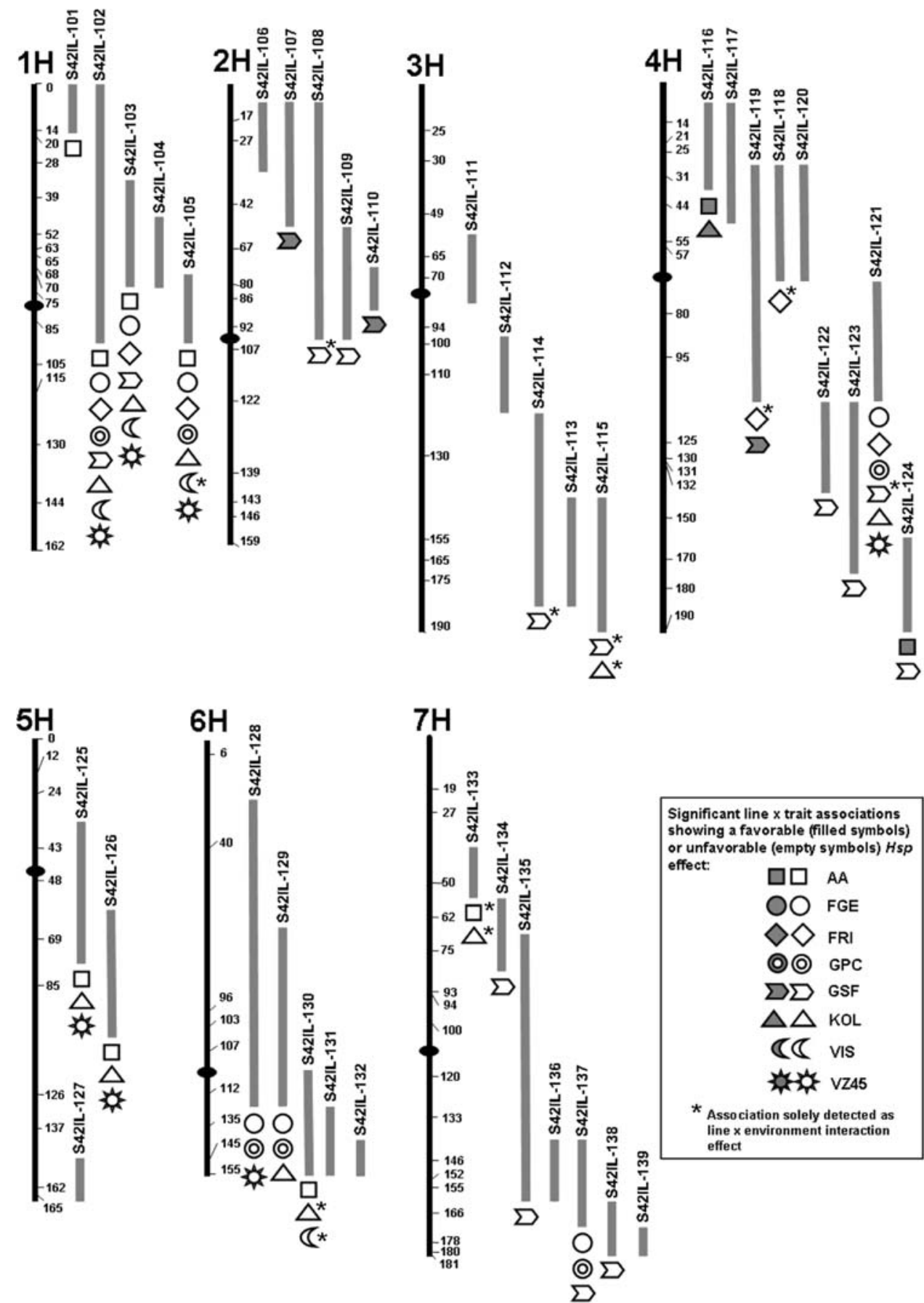

As shown in Table 3, VZ45 indeed revealed high positive correlations with KOL, AA and FRI in the S42IL study ( $r=0.92,0.83$ and 0.73 , respectively). This coincides with multiple QTL effects on these traits, which are predominantly located on chromosomes $1 \mathrm{H}$ and $5 \mathrm{H}$ (Fig. 1). One QTL cluster, localized in the region $1 \mathrm{H}, 0-85 \mathrm{cM}$, corresponds to the map location of several Hor genes coding for different forms of hordein, the major storage protein in barley (Rostoks et al. 2005).
Friability and viscosity

Von Korff et al. (2008) assessed seven QTLs for FRI which are located in chromosomal regions represented by S42ILs. As listed in Table 4, two out of these seven QTLs (28.6\%) were confirmed in the present study and revealed a reducing $H s p$ effect on trait performance in both populations. At QFri.S42-1H.a/QFri.S42IL-1H.a, the exotic genotype decreased FRI by a maximum of 19.4 and $20.0 \%$ 
in population S42 and S42IL-102, respectively. In both verified QTL regions on chromosomes $1 \mathrm{H}$ and $4 \mathrm{H}$, Li et al. (2005) identified a QTL effect on friability. Here, the allele of the Hsp accession 'HS213' was associated with an increased trait value.

In population S42, seven QTLs affecting VIS were mapped to chromosomal regions, which are already represented by the S42IL set. Two out of these seven QTLs (28.6\%) were confirmed by S42ILs. QVis.S42-1H.a and QVis.S42IL-1H.a are located within the chromosomal region 1H, 0-85 cM, which exhibited multiple QTL effects on several traits simultaneously. As described above, one QTL for FRI, associated with a reducing $H s p$ effect, also maps to this region. This coincides with the strong negative correlation between FRI and VIS ( $r=-0.64$, Table 3$)$. Both traits, FRI and VIS, are cytolytic parameters which are mainly affected by the breakdown of $\beta$-glucan, the major constituent of barley endosperm cell walls. Indeed, Han et al. (1995) and Zwickert-Menteur et al. (1996) mapped several QTLs for $\beta$-glucan content and $\beta$-glucanase activity in the 'Steptoe'/'Morex' population to the described region on chromosome $1 \mathrm{H}$. These findings correspond to the locus of Glbl encoding for $(1 \rightarrow 3,1 \rightarrow 4)-\beta$ glucan 4-glucanhydrolase (MacLeod et al. 1991). The second verified QTL for VIS was mapped to the genomic region $6 \mathrm{H}, 112-155 \mathrm{cM}$, and revealed an $H s p$ effect with an opposed direction in the two compared populations. This could be due to the fact, that in the present study this effect was significant solely in environment G07.

\section{Grain protein content and Kolbach index}

Grain protein content is one of the major determinants of malting quality. For GPC, von Korff et al. (2008) identified nine QTLs which were located within chromosomal regions already covered by S42ILs. Indeed, five out of these nine QTLs (55.6\%) were confirmed by the present study, all exhibiting an increasing $H s p$ effect. As mentioned above, the region $1 \mathrm{H}, \quad 0-85 \mathrm{cM}$, harboring QPro.S42-1H.b and QGpc.S42IL-1H.a, corresponds to the map position of several Hor genes (Rostoks et al. 2005). A different organization of these genes could possibly explain the variation in GPC between the exotic and the elite genotype. Pelger et al. (1993) detected differences regarding the number of segregating Hor loci both between two different wild barley species and between them and several forms of $H$. vulgare.

In the S42ILs as well as in population S42, QTL effects on GPC were localized on chromosome arm 6HS. These findings coincide with the localization of QTLs for GPC, nitrogen storage, and nitrogen remobilization detected in a RIL population which was derived from a cross between high- and low-GPC barley cultivars (See et al. 2002;
Mickelson et al. 2003). As See et al. (2002) reported, a major QTL for GPC was localized near SSR marker HVM74. In our present study, this marker maps to the chromosomal region showing the strongest QTL effect on this trait (QGpc.S42IL-6H.a). Based on different studies conducted in wheat and barley, Distelfeld et al. (2008) assumed that sequence polymorphism in the barley NAC transcription factor $H v N A M-1$ could be a possible explanation for this QTL. The wheat ortholog of HvNAM-1 was cloned by Uauy et al. (2006) and proved to be responsible for the regulation of grain protein content in wheat. The exotic HvNAM-1 gene, which was mapped onto the S42ILs -128 and -129 (data not shown) is thus a strong candidate to explain the observed effect on GPC in our study. Further transformation experiments will be conducted to test for this hypothesis.

In addition to the verified QTLs, one new QTL for GPC, revealing an unfavorable exotic effect, was mapped to chromosome 7H (QGpc.S42IL-7H.a). In this region, a further QTL for protein content, also exhibiting an unfavorable $H s p$ effect, was assessed by Li et al. (2005).

For the newly investigated parameter KOL, seven QTL effects, among which one was associated with a favorable increasing effect of the exotic introgression, were mapped to all chromosomes except 2H. The four QTLs QKol.S42IL-1H.a, QKol.S42IL-3H.a, QKol.S42IL-4H.a and QKol.S42IL-5H.a were localized within the same genomic regions as QTLs for KOL identified in the populations 'Dicktoo'/'Morex' and 'Harrington'/'Morex' (Oziel et al. 1996; Marquez-Cedillo et al. 2000). The parameter Kolbach index is conform to the soluble protein/total protein ratio and provides an indication of the proteolytic enzyme content of malt. In fact, QKol.S42IL-3H.a maps to the same chromosome arm as $C e p B$, a gene encoding for malt endopeptidase 1 which hydrolyses hordein (Guerin et al. 1992, 1994).

\section{Grain sieving fraction $>2.5 \mathrm{~mm}$}

For the newly investigated trait GSF, altogether ten putative QTLs were identified by S42ILs, where three QTLs exhibited a favorable exotic effect. For nearly all these regions coincident QTLs can be found in the literature. In region 1H, 0-85 cM containing QGsf.S42IL-1H.a, several QTLs for grain size were identified in the populations 'Blenheim'/'E224/3' and 'Harrington'/'Morex' (Thomas et al. 1995; Powell et al. 1997; Marquez-Cedillo et al. 2000). Since grain size is strongly influenced by the accumulation of storage material, like carbohydrates and proteins, during the grain-filling phase of the post-anthesis period (Coventry et al. 2003), different Hor loci, located within the same region, could be assumed to affect GSF. Furthermore, grain size is indirectly influenced by the 
pre-anthesis period which length is affected by responses to photoperiod and temperature. Thus, as Coventry et al. (2003) underlined, different response genes might be involved in the determination of grain size. Indeed, the major photoperiod response gene of barley, Ppd-H1 (Turner et al. 2005), maps to the same genomic region as QGsf.S42IL-2H.a and QGsf.S42IL-2H.b (Table 4). Moreover, the location of $\mathrm{Vrn}-\mathrm{H} 2$, one of the barley vernalization response genes (Laurie et al. 1995), corresponds to QGsf.S42IL-4H.c. On chromosome 4H, two further QTL effects (QGsf.S42IL-4H.a and QGsf.S42IL4H.b) were identified in the present study, and are consistent with QTLs for kernel plumpness assessed in the populations 'Harrington'/'Morex' and 'Harrington'/ ‘TR306' (Marquez-Cedillo et al. 2000; Mather et al. 1997). The barley photoperiod response gene $\mathrm{HvCOl}$ (Griffiths et al. 2003) and the 'earliness per se' gene eps7L (Laurie et al. 1995) could be assumed to have an effect on GSF at QGsf.S42IL-7H.a and/or QGsf.S42IL-7H.b. Laurie et al. (1995) demonstrated a delay in flowering time in barley caused by the dwarfing gene $s d w 1$ (previously named denso), which maps to the long arm of chromosome $3 \mathrm{H}$ and, thus, could be a candidate gene for GSF at QGsf.S42IL-3H.a. Here, a QTL effect on GSF was also detected by Thomas et al. (1995) and Powell et al. (1997).

\section{Identification of malting quality QTL clusters}

As illustrated in Fig. 1, several chromosomal regions exhibited multiple QTL effects. Two QTL clusters mapping to region $1 \mathrm{H}, 0-85 \mathrm{cM}$ and $4 \mathrm{H}, 80-95 \mathrm{cM}$ are evidently of particular interest as they harbor QTL effects for eight and six malting quality parameters simultaneously. In previous studies using the S42IL set, additional significant effects on the traits grains per ear, days until heading, plant height, lodging at harvest, and resistance to powdery mildew were also identified in both regions (Schmalenbach et al. 2008, 2009). In the present study, QTLs affecting seven or eight malting quality traits in region $1 \mathrm{H}, 0-85 \mathrm{cM}$ were assessed in S42ILs-102, -103 and -105 (Fig. 1). In contrast, S42ILs101 and -104 whose introgressions $(1 \mathrm{H}, 0-14 \mathrm{cM}$ and $1 \mathrm{H}$, $52-70 \mathrm{cM}$, respectively) are completely represented by S42IL-102 revealed one and no significant effect, respectively. Due to these facts, it could be assumed that the exotic segment present in S42IL-103 is further extended towards the centromere than expected on the basis of SSR genotype data, whereas the introgression of S42IL-104 has the expected size. Thus, introgressions of S42ILs-102, -103 and -105 would cover the same genomic region harboring the QTL cluster. However, it is required to verify this hypothesis by genotyping the S42ILs with additional markers, and thus to define the extension of exotic introgressions more precisely.
One hypothesis explaining the occurrence of QTL clusters might be the presence of relatively few genes with pleiotropic effects. Several studies investigating the 'domestication syndrome' in different crop species have supported this assumption by identifying major QTLs as well as major genes directly associated with the domestication process (Bomblies and Doebley 2006; Koinange et al. 1996; Weeden 2007). In contrast, it could be proposed that numerous genes affecting different traits are closely linked within QTL complexes and were fixed during the domestication and breeding process (Xiong et al. 1999). It is advisable to dissect the malting quality QTL clusters identified in the present study and thus to unravel their genetic basis. So far, two malting quality QTL complexes located near the chromosome $4 \mathrm{H}$ telomere and in the chromosome $7 \mathrm{H}$ centromere region were fine-mapped using two sets of barley isolines (Gao et al. 2004; Han et al. 1997, 2004). By means of these lines, which carried either 'Steptoe' or 'Morex' segments of different size in the target region, the QTL complexes on chromosome $4 \mathrm{H}$ and $7 \mathrm{H}$ were resolved to intervals of $0.7-27.9 \mathrm{cM}$ and 2.0-6.4 cM, respectively. A similar study could be conducted using the described S42ILs on chromosomes $1 \mathrm{H}$ and $4 \mathrm{H}$ as initial material for the development of so called SUB-ILs which possess smaller exotic introgressions.

\section{Future prospects}

Exemplified by malting quality, the present study indicates the usefulness of wild barley introgression lines for the localization and verification of QTLs. In future, additional S42ILs harboring exotic introgressions in so far missing genomic regions will be constructed. They could enable the detection of further QTL effects for malting quality as well as for agronomic parameters and disease resistances. In addition, the complete S42IL set will be extensively evaluated with regard to abiotic stress tolerance, i.e. tolerance to drought stress and nutrient deficiency. Through genotyping with Illumina SNPs (Rostoks et al. 2006) or Diversity Arrays Technology (DArT) markers (Wenzl et al. 2006), a more precise characterization of the lines on the genome level is also intended. This will facilitate the selection of SUB-ILs with smaller $H s p$ introgressions, which could be a valuable resource for fine-mapping of QTL clusters and map-based cloning of promising QTL effects. As described above, clustered QTL effects for malting quality which were detected in S42ILs-102, -103, -105 , and -121 on chromosomes $1 \mathrm{H}$ and $4 \mathrm{H}$, respectively, would be of special interest for such high-resolution mapping approaches. Other studies will focus on the investigation of epistatic effects by constructing S42ILs carrying two or several exotic introgressions simultaneously. The first step towards such a set of lines has 
already been done by crossing selected S42ILs. These lines could also be used for QTL pyramiding.

Acknowledgments We are grateful to Dr. L. Kuntze (Nordsaat Saatzucht) and her team for conducting micro malting experiment and analyzing malting quality parameters. Furthermore, we thank Drs. E. Laubach (Nordsaat Saatzucht), J. Breun and H. Kempe (Saatzucht Josef Breun), and W. Bungert and H. Rehkopf (Dikopshof, University of Bonn) and their teams for performing field experiments. We thank A. Bus for mapping the HvNAM-1 gene to S42ILs -128 and -129 . The excellent technical assistance of M. Noschinski is appreciated. This work was funded by the German Plant Genome Research Initiative (GABI) of the Federal Ministry of Education and Research (BMBF, project $0313125 \mathrm{~B})$.

Open Access This article is distributed under the terms of the Creative Commons Attribution Noncommercial License which permits any noncommercial use, distribution, and reproduction in any medium, provided the original author(s) and source are credited.

\section{References}

Ahokas H, Naskali L (1990a) Geographic variation of $\alpha$-amylase, $\beta$-amylase, $\beta$-glucanase, pullulanase and chitinase activity in germinating Hordeum spontaneum from Israel and Jordan. Genetica 82:73-78

Ahokas H, Naskali L (1990b) Variation of $\alpha$-amylase, $\beta$-amylase, $\beta$-glucanase, pullulanase, proteinase and chitinase activity in germinated samples of the wild progenitor of barley. J Inst Brew 96:27-31

Barr AR, Jefferies SP, Broughton S, Chalmers KJ, Kretschmer JM, Boyd WJR, Collins HM, Roumeliotis S, Logue SJ, Coventry SJ, Moody DB, Read BJ, Poulsen D, Lance RCM, Platz GJ, Park RF, Panozzo JF, Karakousis A, Lim P, Verbyla AP, Eckermann PJ (2003a) Mapping and QTL analysis of the barley population Alexis $\times$ Sloop. Aust J Agr Res 54:1117-1123

Barr AR, Karakousis A, Lance RCM, Logue SJ, Manning S, Chalmers KJ, Kretschmer JM, Boyd WJR, Collins HM, Roumeliotis S, Coventry SJ, Moody DB, Read BJ, Poulsen D, Li CD, Platz GJ, Inkerman PA, Panozzo JF, Cullis BR, Smith AB, Lim P, Langridge P (2003b) Mapping and QTL analysis of the barley population Chebec $\times$ Harrington. Aust J Agr Res 54:1125-1130

Bomblies K, Doebley JF (2006) Pleiotropic effects of the duplicate maize FLORICAULA/LEAFY genes $z f l 1$ and $z f l 2$ on the traits under selection during maize domestication. Genetics 172:519_ 531

Choi DW, Koag MC, Close TJ (2000) Map locations of barley Dhn genes determined by gene-specific PCR. Theor Appl Genet 101:350-354

Choi DW, Rodriguez EM, Close TJ (2002) Barley Cbf3 gene identification, expression pattern, and map location. Plant Physiol 129:1781-1787

Clark SE, Hayes PM, Henson CA (2003) Effects of single nucleotide polymorphisms in beta-amylase 1 alleles from barley on functional properties of the enzymes. Plant Physiol Biochem 41:798-804

Collins HM, Panozzo JF, Logue SJ, Jefferies SP, Barr AR (2003) Mapping and validation of chromosome regions associated with high malt extract in barley (Hordeum vulgare L.). Aust J Agr Res 54:1223-1240

Costa JM, Corey A, Hayes PM, Jobet C, Kleinhofs A, KopischObusch A, Kramer SF, Kudrna D, Li M, Riera-Lizarazu O, Sato
K, Szucs P, Toojinda T, Vales MI, Wolfe RI (2001) Molecular mapping of the Oregon Wolfe barleys: a phenotypically polymorphic doubled-haploid population. Theor Appl Genet 103:415-424

Coventry SJ, Barr AR, Eglinton JK, McDonald GK (2003) The determinants and genome locations influencing grain weight and size in barley (Hordeum vulgare L.). Aust J Agr Res 54:11031115

Distelfeld A, Korol A, Dubcovsky J, Uauy C, Blake T, Fahima T (2008) Colinearity between the barley grain protein content (GPC) QTL on chromosome arm 6HS and the wheat $G p c-B 1$ region. Mol Breed 22:25-38

Dunnett CW (1955) A multiple comparison procedure for comparing several treatments with a control. J Am Stat Assoc 50:10961121

Edney MJ, Mather DE (2004) Quantitative trait loci affecting germination traits and malt friability in a two-rowed by six rowed barley cross. J Cereal Sci 39:283-290

Eduardo I, Arus P, Monforte AJ, Obando J, Fernandez-Trujillo JP, Martinez JA, Alarcon AL, Alvarez JM, van der Knaap E (2007) Estimating the genetic architecture of fruit quality traits in melon using a genomic library of near isogenic lines. J Am Soc Hortic Sci 132:80-89

Emebiri LC, Moody DB, Panozzo JF, Chalmers KJ, Kretschmer JM, Ablett GA (2003) Identification of QTLs associated with variations in grain protein concentration in two-row barley. Aust J Agr Res 54:1211-1221

Emebiri LC, Moody DB, Panozzo JF, Read BJ (2004) Mapping of QTL for malting quality attributes in barley based on a cross of parents with low grain protein concentration. Field Crops Res 87:195-205

Emebiri LC, Mood DB, Horsley R, Panozzo J, Read BJ (2005) The genetic control of grain protein content variation in a doubled haploid population derived from a cross between Australian and North American two-rowed barley lines. J Cereal Sci 41:107-114

EBC, European Brewery Convention (2005) Analytica-EBC. Fachverlag Hans Carl, Nürnberg, Germany, ISBN: 3-418-00759-7

Falke KC, Sušić Z, Hackauf B, Korzun V, Schondelmaier J, Wilde P, Wehling P, Wortmann H, Mank R, van der Rouppe Voort J, Maurer HP, Miedaner T, Geiger HH (2008) Establishment of introgression libraries in hybrid rye (Secale cereale L.) from an Iranian primitive accession as a new tool for rye breeding and genomics. Theor Appl Genet 117:641-652

Fernandez-Trujillo JP, Obando J, Martinez JA, Alarcon AL, Eduardo I, Arus P, Monforte AJ (2007) Mapping fruit susceptibility to postharvest physiological disorders and decay using a collection of near-isogenic lines of melon. J Am Soc Hortic Sci 132:739_ 748

Fox GP, Panozzo JF, Li CD, Lance RCM, Inkerman PA, Henry RJ (2003) Molecular basis of barley quality. Aust J Agr Res 54:1081-1101

Gao W, Clancy JA, Han F, Jones BL, Budde A, Wesenberg DM, Kleinhofs A, Ullrich SE, North American Barley Genome Project (2004) Fine mapping of a malting-quality QTL complex near the chromosome $4 \mathrm{H} \mathrm{S}$ telomere in barley. Theor Appl Genet 109:750-760

Griffiths S, Dunford RP, Coupland G, Laurie DA (2003) The evolution of CONSTANS-like gene families in barley, rice, and Arabidopsis. Plant Physiol 131:1855-1867

Guerin JR, Lance RCM, Wallace W (1992) Chromosomal location of a barley malt endopeptidase gene. Genet Res 59:179-181

Guerin JR, Lance RCM, Brown AHD, Abbott DC (1994) Mapping of malt endopeptidase, NADH diaphorase and esterase loci on barley chromosome 3L. Plant Breed 112:279-284

Han F, Ullrich SE, Chirat S, Menteur S, Jesting L, Sarrafi O, Hayes MP, Jones BL, Blake TK, Wesenberg D, Kleinhofs A, Kilian A 
(1995) Mapping of $\beta$-glucan content and $\beta$-glucanase activity loci in barley grain and malt. Theor Appl Genet 91:921-927

Han F, Ullrich SE, Kleinhofs A, Jones BL, Hayes PM, Wesenberg DM (1997) Fine structure mapping of the barley chromosome-1 centromere region containing malting-quality QTLs. Theor Appl Genet 95:903-910

Han F, Clancy JA, Jones BL, Wesenberg DM, Kleinhofs A, Ullrich SE (2004) Dissection of a malting quality QTL region on chromosome $1(7 \mathrm{H})$ of barley. Mol Breed 14:339-347

Hayes PM, Castro A, Marquez-Cedillo L, Corey A, Henson C, Jones BL, Kling J, Mather D, Matus I, Rossi C, Sato K (2003) Genetic diversity for quantitatively inherited agronomic and malting quality traits. In: Von Bothmer R, Van Hintum T, Knupffer H, Sato K (eds) Diversity in barley (Hordeum vulgare). Elsevier, New York, pp 147-169

SAS Institute (2006) The SAS Enterprise Guide for Windows, release 4.1. SAS Institute, Cary, NC, USA

Kleinhofs A, Graner A (2001) An integrated map of the barley genome. Kluwer, Dordrecht, pp 187-199

Koinange EMK, Singh SP, Gepts P (1996) Genetic control of the domestication syndrome in common bean. Crop Sci 36:10371045

Laurie DA, Pratchett N, Bezant JH, Snape JW (1995) RFLP mapping of 5 major genes and 8 quantitative trait loci controlling flowering time in a winter $\times$ spring barley (Hordeum vulgare $\mathrm{L}$.) cross. Genome 38:575-585

Li J, Huang XQ, Heinrichs F, Ganal MW, Röder MS (2005) Analysis of QTLs for yield, yield components, and malting quality in a $\mathrm{BC}_{3} \mathrm{DH}$ population of spring barley. Theor Appl Genet 110:356363

Liu SW, Zhao SY, Chen F, Xia GM (2007) Generation of novel high quality HMW-GS genes in two introgression lines of Triticum aestivum/Agropyron elongatum. BMC Evol Biol 7:76

MacLeod LC, Lance RCM, Brown AHD (1991) Chromosomal mapping of the Glb1 locus encoding $(1 \rightarrow 3,1 \rightarrow 4)$ - $\beta$-D-glucan 4-glucanhydrolase EI in barley. J Cereal Sci 13:291-298

Marquez-Cedillo LA, Hayes PM, Jones BL, Kleinhofs A, Legge WG, Rossnagel BG, Sato K, Ullrich E, Wesenberg DM, The North American Barley Genome Project (2000) QTL analysis of malting quality in barley based on the doubled-haploid progeny of two elite North American varieties representing different germplasm groups. Theor Appl Genet 101:173-184

Mather DE, Tinker NA, LaBerge DE, Edney M, Jones BL, Rossnagel BG, Legge WG, Briggs KG, Irvine RB, Falk DE, Kasha KJ (1997) Regions of the genome that affect grain and malt quality in a North American two-row barley cross. Crop Sci 37:544-554

Matus I, Corey A, Filichkin T, Hayes PM, Vales MI, Kling J, RieraLizarazu O, Sato K, Powell W, Waugh R (2003) Development and characterization of recombinant chromosome substitution lines (RCSLs) using Hordeum vulgare subsp spontaneum as a source of donor alleles in a Hordeum vulgare subsp vulgare background. Genome 46:1010-1023

Mickelson S, See D, Meyer FD, Garner JP, Foster CR, Blake TK, Fischer AM (2003) Mapping of QTL associated with nitrogen storage and remobilization in barley (Hordeum vulgare L.) leaves. J Exp Bot 54:801-812

MEBAK, Mitteleuropäische Brautechnische Analysenkommission (1997) Methodensammlung der Mitteleuropäischen Analysenkommission. Band I, 3. Auflage: Rohstoffe-Wasser, Gerste, Rohfrucht, Malz, Hopfen und Hopfenprodukte, ISBN 3-9805814-0-3

Obando J, Fernandez-Trujillo JP, Martinez JA, Alarcon AL, Eduardo I, Arus P, Monforte AJ (2008) Identification of melon fruit quality quantitative trait loci using near-isogenic lines. J Am Soc Hortic Sci 133:139-151
Oziel A, Hayes PM, Chen FQ, Jones B (1996) Application of quantitative trait locus mapping to the development of winterhabit malting barley. Plant Breed 115:43-51

Panozzo JF, Eckermann PJ, Mather DE, Moody DB, Black CK, Collins HM, Barr AR, Lim P, Cullis BR (2007) QTL analysis of malting quality traits in two barley populations. Aust J Agr Res $58: 858-866$

Pelger S, Sall T, Bengtsson BO (1993) Evolution of hordein gene organization in three Hordeum species. Hereditas 119:219-231

Pillen K, Zacharias A, Léon J (2003) Advanced backcross QTL analysis in barley (Hordeum vulgare L.). Theor Appl Genet 107:340-352

Pillen K, Zacharias A, Léon J (2004) Comparative AB-QTL analysis in barley using a single exotic donor of Hordeum vulgare ssp. spontaneum. Theor Appl Genet 108:1591-1601

Powell W, Thomas WTB, Baird E, Lawrence P, Booth A, Harrower B, McNicol JW, Waugh R (1997) Analysis of quantitative traits in barley by the use of amplified fragment length polymorphisms. Heredity 79:48-59

Rae SJ, Macaulay M, Ramsay L, Leigh F, Matthews D, O'Sullivan DM, Donini P, Morris PC, Powell W, Marshall DF, Waugh R, Thomas WTB (2007) Molecular barley breed. Euphytica 158:295-303

Rostoks N, Mudie S, Cardle L, Russell J, Ramsay L, Booth A, Svensson JT, Wanamaker SI, Walia H, Rodriguez EM, Hedley PE, Liu H, Morris J, Close TJ, Marshall DF, Waugh R (2005) Genome-wide SNP discovery and linkage analysis in barley based on genes responsive to abiotic stress. Mol Genet Genomics 274:515-527

Rostoks N, Ramsay L, MacKenzie K, Cardle L, Bhat PR, Roose ML, Svensson JT, Stein N, Varshney RK, Marshall DF, Graner A, Close TJ, Waugh R (2006) Recent history of artificial outcrossing facilitates whole-genome association mapping in elite inbred crop varieties. Proc Natl Acad Sci USA 103:18656-18661

Rousseaux MC, Jones CM, Adams D, Chetelat R, Bennett A, Powell A (2005) QTL analysis of fruit antioxidants in tomato using Lycopersicon pennellii introgression lines. Theor Appl Genet 111:1396-1408

Schmalenbach I, Körber N, Pillen K (2008) Selecting a set of wild barley introgression lines and verification of QTL effects for resistance to powdery mildew and leaf rust. Theor Appl Genet 117:1093-1106

Schmalenbach I, Léon J, Pillen K (2009) Identification and verification of QTLs for agronomic traits using wild barley introgression lines. Theor Appl Genet 118:483-497

See D, Kanazin V, Kephart K, Blake T (2002) Mapping genes controlling variation in barley grain protein concentration. Crop Sci 42:680-685

Thomas WTB (2003) Prospects for molecular breeding of barley. Ann Appl Biol 142:1-12

Thomas WTB, Powell W, Waugh R, Chalmers KJ, Barua UM, Jack P, Lea V, Forster BP, Swanston JS, Ellis RP, Hanson PR, Lance RCM (1995) Detection of quantitative trait loci for agronomic, yield, grain and disease characters in spring barley (Hordeum vulgare L.). Theor Appl Genet 91:1037-1047

Turner A, Beales J, Faure S, Dunford RP, Laurie DA (2005) The pseudo-response regulator $\mathrm{Ppd}-\mathrm{H} 1$ provides adaptation to photoperiod in barley. Science 310:1031-1034

Uauy C, Brevis JC, Dubcovsky J (2006) The high grain protein content gene $G p c-B 1$ accelerates senescence and has pleiotropic effects on protein content in wheat. J Exp Bot 57:2785-2794

von Korff M, Wang H, Léon J, Pillen K (2004) Development of candidate introgression lines using an exotic barley accession (Hordeum vulgare ssp. spontaneum) as donor. Theor Appl Genet 109:1736-1745 
von Korff M, Wang H, Léon J, Pillen K (2008) AB-QTL analysis in spring barley: III. Identification of exotic alleles for the improvement of malting quality in spring barley $(H$. vulgare ssp. spontaneum). Mol Breed 21:81-93

Weeden NF (2007) Genetic changes accompanying the domestication of Pisum sativum: is there a common genetic basis to the 'domestication syndrome' for legumes. Ann Bot-London 100: $1017-1025$

Wenzl P, Li HB, Carling J, Zhou MX, Raman H, Paul E, Hearnden P, Maier C, Xia L, Caig V, Ovesna J, Cakir M, Poulsen D, Wang JP, Raman R, Smith KP, Muehlbauer GJ, Chalmers KJ, Kleinhofs A, Huttner E, Kilian A (2006) A high-density consensus map of barley linking DArT markers to SSR, RFLP and STS loci and agricultural traits. BMC Genomics 7:206

Xiong LZ, Liu KD, Dai XK, Dai XK, Xu CG, Zhang Q (1999) Identification of genetic factors controlling domestication-related traits of rice using an $\mathrm{F}_{2}$ population of a cross between Oryza sativa and $O$. rufipogon. Theor Appl Genet 98:243-251

Zamir D (2001) Improving plant breeding with exotic genetic libraries. Nat Rev Genet 2:983-989

Zhang WS, Li X, Liu JB (2007) Genetic variation of Bmyl alleles in barley (Hordeum vulgare L.) investigated by CAPS analysis. Theor Appl Genet 114:1039-1050

Zheng TQ, Xu JL, Li ZK, Zhai HQ, Wan JM (2007) Genomic regions associated with milling quality and grain shape identified in a set of random introgression lines of rice (Oryza sativa L.). Plant Breed 126:158-163

Zwickert-Menteur S, Jestin L, Branlard G (1996) Amy2 polymorphism as a possible marker of $\beta$-glucanase activity in barley (Hordeum vulgare L). J Cereal Sci 24:55-63 